\title{
A REFERENCE MODEL FOR KNOWLEDGE RETENTION WITHIN SMALL AND MEDIUM-SIZED ENTERPRISES
}

\author{
Quang Minh DOAN ${ }^{1}$, Camille Rosenthal-Sabroux ${ }^{1}$ and Michel Grundstein ${ }^{1,2}$ \\ ${ }^{I}$ Paris Dauphine University, Lamsade CNRS, UMR7024, F-75016 Paris, France \\ ${ }^{2}$ MG Conseil, Nogent sur Marne, 94130, France \\ doanquangminh@neu.edu.vn,sabroux@lamsade.dauphine.fr,mgrundstein@mgconseil.fr
}

\begin{abstract}
Keywords: Critical knowledge, crucial knowledge, knowledge retention (KR), reference model for knowledge retention within SMEs (KR-SME).

Abstract: $\quad$ Knowledge retention (KR) has been identified as one of the critical factors for maintaining sustainable performance. However, until recently, most of the existing researches have focused on large organizations, while very few studies have mentioned this issue in Small and Medium-Sized Enterprises (SMEs). To redress some of this imbalance in the literature, this paper provides a reference model for knowledge retention within SMEs. This model includes most of the fundamental elements that are believed to be critical for an effective KR implementation. The model is especially tailored for SMEs to kick-start a KR initiative in their organization as well as can be served as a template to assess the SMEs' KR maturity level.
\end{abstract}

\section{INTRODUCTION}

For organizations in today's modern economy, knowledge is regarded as one of the elements to gain sustainable competitive advantage over competitors. Those organizations that are "continuously learning," adaptive and agile will be the most likely to survive. Part of reaching that goal is based on harnessing and leveraging the human capital in the organization. That is where knowledge retention (KR) and transfer techniques can be used to capture, share, apply, leverage and possibly create knowledge before employees leave the organization, or to onboard new employees to quickly get them up to speed. Organizations that are embracing knowledge retention activities are gaining a competitive advantage (Liebowitz, 2011). Knowledge retention and transfer is an area that holds great potential for companies in terms of reducing the costs associated with turnover, and perhaps more important, in sustaining business performance (Manpower Inc., 2010). Due to this fact, today's SMEs are more and more concerned with $\mathrm{KR}$ as a key factor for improving their efficiency and competitiveness for the reason that they are often more vulnerable than larger organizations in terms of losing key personnel.
Consequently, a KR model for SMEs is necessary since most of the existing $\mathrm{KR}$ researches have mainly focused on solutions to mitigate the impact of critical knowledge loss in large organizations.

The objective of this paper is to propose a reference model for knowledge retention within SMEs (KR-SME). This model includes most of the fundamental elements that are believed to be critical for an effective KR implementation. The model is especially tailored for SMEs to kick-start a $\mathrm{KR}$ initiative in their organization as well as can be served as a template to assess the SMEs' KR maturity level. In order to achieve this purpose, a systemic and comparative scientific literature analysis was selected to investigate and synthesize the most critical factors that influence knowledge retention effectiveness in organizations in general and within the context of SMEs in particular.

The remainder of this paper is structured as follows. Firstly, an overview of the background theory in knowledge retention is presented. Secondly, the existing studies, frameworks, and models that have already identified the key factors potentially affecting SMEs' KR success are analyzed. Finally, the reference model for knowledge retention within SMEs is developed. 


\section{BACKGROUND THEORY}

\subsection{Knowledge}

A definition of $\mathrm{KM}$ in general and $\mathrm{KR}$ in particular will not be completed without initially understanding the characteristics and differences between data, information and knowledge. Data and information are often misunderstood to be synonymous with knowledge. According to Davenport and Prusak (1998), data is a set of discrete, objective facts about events. Data itself does not allow for judgment or interpretation. It represents the raw materials used in organizations for the purpose of creating information. Alavi and Leidner (2001) suggest that information becomes knowledge once it is processed in the mind of individuals and knowledge becomes information once it is presented in the form of text, graphics, words or other symbolic forms. Davenport and Prusak (1998) define knowledge as a "fluid mix of framed experiences, values, contextual information and expert insight that provides a framework for evaluating and incorporating new experiences and information. It originates and is applied in the minds of knower's. In organizations, it often becomes embedded not only in documents or repositories but also in organizational routines, processes, practices, and norms".

\section{$2.2 \quad$ Types of Knowledge}

According to most KM theorists, knowledge can be explicit or tacit (Nonaka and Takeuchi, 1995; Sveiby, 1997; Davenport and Prusak, 1998; Pan and Scarborough, 1999). Explicit knowledge is knowledge that has been or can be articulated, codified, and stored in certain media and can be readily transmitted to others. Similarly, Pan and Scarborough (1999) believe that the explicit part of knowledge is systematic and easy to communicate in the form of hard data or codified procedures. This means that explicit form of knowledge can be transmitted across individuals formally and easily. Tacit knowledge, however, is created through learning by doing, it is difficult to express, formalize, or transfer (Sveiby, 1997). Tacit knowledge is found embedded in action, commitment, and involvement in a specific context and it is also derived from personal experiences; it is subjective as well as difficult to formalize (Nonaka et al., 2000). In implementing and practicing KM, these distinctions must be well understood; only information and explicit knowledge can be exchanged through documents, while the more important tacit knowledge can only be exchanged by human interaction. Nevertheless, both types of knowledge are important and interdependent. Therefore, when implementing KR initiatives, SMEs should consider identifying, capturing, transferring, storing, and applying critical knowledge at risk, which is not only in tacit but also in explicit form as well.

\subsection{Critical Knowledge}

Kaplan (2010) defined critical knowledge as knowledge that is fundamental to the business or operational processes of the organization that support mission delivery and mission success. According to this point of view, critical knowledge is often related to the activities of the target business processes within organizations.

Jung et al. (2007) also confirmed that, for organizations, it is important to focus on processrelated knowledge which is created and used within a business process and can be used by activity performers when a business process is actually executed. The concept of process-related knowledge will also enable enterprises to filter valuable knowledge and to avoid information overload.

Similarly, Grundstein and Rosenthal-Sabroux (2008) introduced the concept of crucial knowledge, which is the knowledge (explicit or tacit) that is essential for decision-making and the progress of value-adding processes. The reasons for this type of knowledge is considered crucial are due to its vulnerability (scarcity, accessibility, cost and delay of acquisition) and its influence on the company's life, markets and strategy. Moreover, the authors also developed a constructivist and learning approach (namely GAMETH ${ }^{\circledR}$ ) to identify and locate crucial knowledge.

Based on the discussion above, in this paper, the two notions critical and crucial knowledge are considered often related to the activities of business processes within organizations and can be somewhat interchangeable. It depends on the KR maturity level of enterprises. For example, if the KR maturity of a company is at initial level (level 1), so the concept of critical knowledge should be used to strongly focus on the most significant and urgent business issues that may lead to the company's success or failure when implementing the knowledge retention process. In contrast, if the KR maturity of the company is already at optimized level (level 5), in this case, the concept of crucial knowledge should be introduced since the knowledge retention 
activities have been embedded as part of everyone's daily work activities.

\subsection{Knowledge Retention}

According to Kirsch (2008), knowledge retention is about focusing on the critical knowledge that is at risk of loss, prioritizing what is at risk based on potential knowledge gaps and their impact upon overall organizational performance, and then developing actionable plans to retain that knowledge.

The following are three specific questions that must be asked when considering knowledge retention and any potential risk of loss of knowledge:

1. What knowledge may be lost?

2. What are the organizational consequences of losing that knowledge?

3. What actions can be taken to retain that knowledge?

One of the most significant challenges for any organization is to get on the "front edge" of any potential knowledge retention challenge rather than waiting until organizational knowledge "walks out the door" (or is walking toward the door, such as in typical "exit interview" efforts to retain knowledge). The organization should focus knowledge harvesting efforts on obtaining as much information about its projects and processes, including the implicit knowledge that is often not directly documented.

A key reason for performing knowledge retention is to grow the institutional memory of the organization. In this manner, employees can learn from past successes and failures to ensure positive results. Learning from others could help avoid going down the wrong paths or reinventing the wheel (Liebowitz, 2009).

Knowledge retention is an important part of knowledge management. According to Daniel Alpert at the University of Oklahoma, knowledge retention strategies improve innovation, organizational growth, efficiency, employee development, and competitive advantage. At the UNESCO meeting on High Level Group of Visionaries on Knowledge Acquisition and Sharing, which met in June 2007, they stressed the need for improved knowledge acquisition models and strategies (Liebowitz, 2009).

\section{KEY SUCCESS FACTORS}

In this section, the existing studies, frameworks, and models related to knowledge management in general and knowledge retention in particular are analyzed to synthesize the key factors potentially affecting the success of knowledge retention process within the context of SMEs.

A wide range of success factors for a knowledge management implementation have been identified in the literature. One of the earliest studies of knowledge management critical factors was presented by Skyrme and Amidon (1997). They highlighted seven key success factors, including $a$ strong link to business imperative, a compelling vision and architecture, knowledge leadership, knowledge creating and sharing culture, continuous learning, a well-developed technology infrastructure, and systematic organizational knowledge processes.

Davenport et al. (1998) conducted a study to explore the practices of $31 \mathrm{KM}$ projects in 24 companies, with the aim of determining the factors associated with the effectiveness. For those projects that were considered successful, eight major factors were identified. These factors included linking knowledge management to economic performance or industry value, a clear purpose and language, a standard and flexible knowledge structure, multiple channels for knowledge transfer, culture, technical and organizational infrastructure, change in motivational practices, and senior management support.

In the same way, Liebowitz (1999) proposed six key factors for making KM successful in organizations. He suggested the need for $a K M$ strategy with support of senior management, a Chief Knowledge Officer (CKO) or equivalent and a knowledge management infrastructure, knowledge ontologies and repositories, knowledge management systems and tools, incentives to encourage knowledge sharing, and supportive culture.

In order to develop a conceptual framework for knowledge management, Stankosky and Baldanza (2000) have considered organization, technology, leadership and learning as the four pillars of KM.

Similarly, Chourides et al. (2003) highlighted five critical factors for KM namely, strategy, human resource management (HRM), information technology, quality, and marketing.

Likewise, Mathi (2004) proposed four factors which determine knowledge management success in an organization including culture, knowledge management organization, systems and information technology infrastructure, effective and systematic processes and measures. 
Wong and Aspinwall (2005) empirically identified eleven critical success factors for adopting knowledge management within SMEs, including management leadership and support, culture, strategy and purpose, resources, processes and activities, training and education, human resource management, information technology, motivational aids, organizational infrastructure, and measurement. According to the authors, these factors were ranked based on the levels of their importance influencing SMEs in adopting KM. Consequently, it is easy to recognize that top management support, culture, and strategy were considered as the most important factors, while organizational infrastructure and measurement were believed to have lower influence on the KM adoption within SMEs. This finding also supports their opinion when these researchers believed that SMEs will have distinct advantages for implementing KM since their structures are often simple, flatter, and not very complex compared to large organizations (Wong and Aspinwall, 2004).

Grundstein (2008) presented a model for general knowledge management within the enterprise (MGKME). This model was composed of two main categories of elements: (i) the underlying elements consist of socio-technical environment, and valueadding processes; (ii) the operating elements focus on the underlying elements (managerial guiding principles, ad hoc infrastructures, generic knowledge management processes, organizational learning processes, and methods and supporting tools). Socio-technical environment constitutes the relations and interactions between information and communication technologies, structure and people.

Recognizing the importance of $\mathrm{KM}$ to the economies of its member countries, and in particular its importance to SMEs, the Asian Productivity Organization (APO) commissioned a fact-finding mission to leading KM institutions and practitioners in Europe and the USA in May 2007 to study the latest trends and developments in KM and to share their best practices with the rest of Asia. Following that mission, an Expert Group was convened to formulate an APO KM framework that would be practical and easy to implement specifically in the Asian SME context (Nair and Kamlesh, 2009). In this framework, four success factors were identified namely leadership, processes, people, and technology.

In order to investigate the drivers of knowledge worker retention, Nelson and McCann (2010) conducted an empirical study in 150 organizations including SMEs and large enterprises, operating in a wide range of industries, and mostly located in the United States, Canada, and Europe. The result showed that strategic knowledge orientation, learning culture, and HR practices are three critical factors directly effecting on the successful retention of knowledge workers within companies.

Recently, Kong et al. (2011) have suggested that companies should take a strategic approach in developing HR practices enabling the development of knowledge and learning capabilities to foster organizational innovation. These researchers claim that $H R$ practices play a key role in retaining organizational knowledge. This point of view has also been supported by a large numbers of scholars since they have argued that knowledge is dependent on people and therefore KM must be related to HR practices, such as recruitment and selection, education and development, pay and reward, and performance management (Carter and Scarbrough, 2001; Hunter et al., 2002; Evans, 2003; Currie and Kerrin, 2003).

After systematically reviewing and analyzing the studies mentioned above, especially based on the findings of recent empirical researches, the authors have summarized and classified the most important factors potentially influencing the success of the knowledge retention process within SMEs in five main categories as follows: top management support, knowledge retention strategy, learning culture, human resource practices, and information and communication technology (ICT) tools.

The list below presents the factors together with their sources:

1. Top management support (Skyrme and Amidon, 1997; Davenport et al., 1998; Liebowitz, 1999; Stankosky and Baldanza, 2000; Wong and Aspinwall, 2005; Nair and Kamlesh, 2009).

2. Knowledge retention strategy (Skyrme and Amidon, 1997; Davenport et al., 1998; Liebowitz, 1999; Chourides et al., 2003; Wong and Aspinwall, 2005; Grundstein, 2008; Nelson and McCann, 2010).

3. Learning culture (Skyrme and Amidon, 1997; Davenport et al., 1998; Liebowitz, 1999; Stankosky and Baldanza, 2000; Mathi, 2004; Wong and Aspinwall, 2005; Grundstein, 2008; Nelson and McCann, 2010).

4. Human resource practices (Carter and Scarbrough, 2001; Hunter et al., 2002; Evans, 2003; Currie and Kerrin, 2003; Chourides et al., 2003; Wong and Aspinwall, 2005; Grundstein, 2008; Nair and Kamlesh, 2009; Nelson and McCann, 2010; Kong et al., 2011). 
5. ICT tools (Skyrme and Amidon, 1997; Davenport et al., 1998; Liebowitz, 1999; Stankosky and Baldanza, 2000; Chourides et al., 2003; Mathi, 2004; Wong and Aspinwall, 2005; Grundstein, 2008; Nair and Kamlesh, 2009).

\section{KR-SME MODEL}

Based on the discussion above, a reference model for knowledge retention within SMEs (KR-SME) has been developed (Figure 1). The model includes the key elements that are believed to be critical for fostering and facilitating the knowledge retention process within organizations.

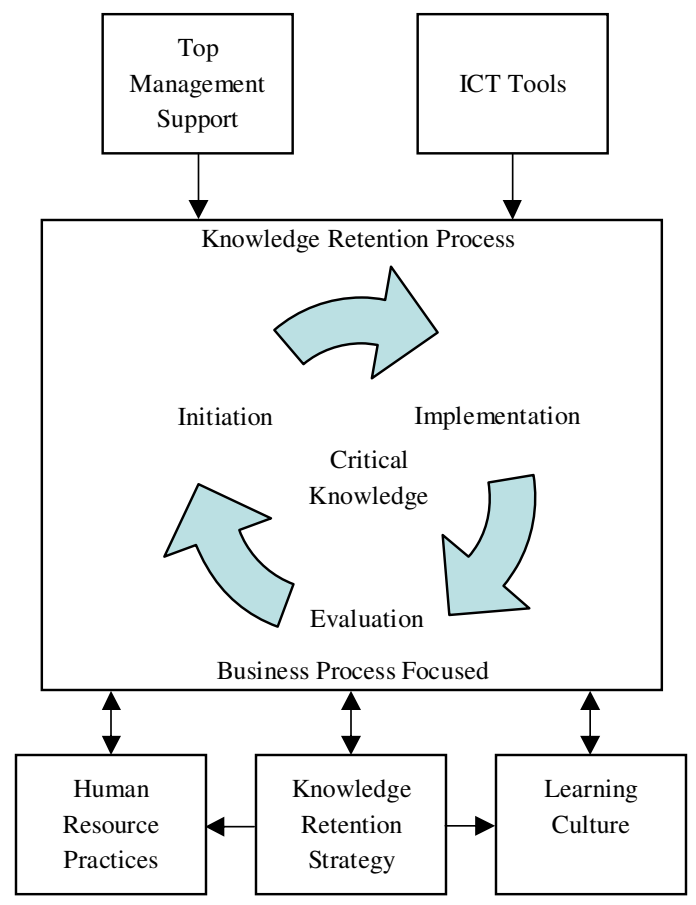

Figure 1: Model for Knowledge Retention within SMEs.

The main elements of the KR-SME model, including knowledge retention process; top management support; KR strategy; learning culture; HR practices; and ICT tools, are explained as follows:

- According to Wright (2007), knowledge retention process consists of three stages: (i) initiation - organizations will indentify positions/individuals where the potential for critical knowledge loss is greatest and most imminent; (ii) implementation organizations will address the potential critical knowledge loss as well as will develop and implement knowledge retention plans. At this stage, the process-related knowledge that is at risk of loss will be captured, transferred, stored, and reapplied effectively; (iii) evaluation - organizations are able to monitor the status of the implementation of knowledge retention process and evaluate the success of knowledge retention plans in accomplishing stated goals. It is also necessary to assess the impact of knowledge retention process on overall organizational performance.

- Top management support refers to the degree to which top managers acting as role models when participating in knowledge retention activities and establishing all the necessary conditions for knowledge retention process as well as will provide additional resources if considered necessary.

- Knowledge retention strategy consists of four main constructs: alignment with business strategy, transparency, feasibility, and flexibility. Alignment with business strategy refers to the degree to which knowledge retention strategy is supporting business strategy. Transparency refers to the extent to which the objectives, goals, and action plans for knowledge retention process are expressed clearly. Feasibility refers to degree of success when implementing knowledge retention plans based on the existing resources and culture of organizations. Flexibility refers to the extent to which knowledge retention strategy can be adapted when having the change in business environment.

- Learning culture is characterized by four main constructs: teamwork, collaboration, adaptability, and solidarity. Teamwork refers to the degree to which people in an organization are encouraged to work in team. Collaboration is a degree of active support and help among individuals within an organization (Lee and Choi, 2003). Adaptability refers to the extent to which individuals expresses their attitude toward learning, takes risk and creates change (Fey and Denison, 1999). Solidarity refers to the degree to which members of an organization share goals and tasks (Goffee and Jones, 1996).

- Human resource practices comprise five main constructs: staffing, job design, performance appraisal systems, reward and 
compensation systems, and training and development. Staffing refers to the extent to which companies consider personenvironment fit to ensure congruence of individual and organizational values and goals that will facilitate knowledge sharing among employees when conducting recruitment and selection procedures (Cabrera and Cabrera, 2005). Job design refers to the degree to which employees will be assigned to positions that are consistent with their skills and abilities since it can influence workers' motivation, and opportunities to use their knowledge (Kelloway and Barling, 2000). Further more; team-based work design can increase social interactions among team members which is likely to facilitate knowledge sharing behavior. Performance appraisal systems refer to the extent to which companies evaluate individual performance when considering knowledge sharing ability as one of the main performance criteria. Reward and compensation systems refer to the degree to which people who involve in knowledge transfer activities will be recognized and rewarded. Training and development refer to the extent to which employees will be provided great opportunities for personal growth and career advancement.

- ICT tools refer to the extent to which ICT applications can be used to facilitate the process of knowledge retention.

The KR-SME model can provide a holistic view and better understanding of how the knowledge retention could be practiced within SMEs. Furthermore, it also can be used as a reference model for effectively implementing the knowledge retention process in small and medium-sized companies.

\section{CONCLUSIONS}

In today's business environment, knowledge management in general and knowledge retention in particular are considered as the main source of competitive advantage for any type of organizations, especially for those belonging to the SME sector since they are often more vulnerable than larger organizations in terms of losing key personnel. However, it seems that knowledge retention specifically in the context of small and medium-sized enterprises has not attracted much research efforts as little information is available about the knowledge retention within SMEs. Due to this fact, this paper attempts to fill some of the gap in the literature by providing the reference model for knowledge retention within SMEs (KR-SME).

This model includes most of the fundamental elements that are believed to be critical for an effective knowledge retention implementation, including knowledge retention process; top management support; knowledge retention strategy; learning culture; human resource practices; and information and communication tools. The model is especially tailored for SMEs to kick-start a knowledge retention initiative in their organization as well as can be served as a template to assess the SMEs' KR maturity level.

\section{REFERENCES}

Alavi, M., Leidner, D. E., 2001. Review: Knowledge Management and Knowledge Management Systems: Conceptual Foundations and Research Issues. MIS Quarterly. 25, 107-136.

Cabrera, E. F., Cabrera, A., 2005. Fostering knowledge sharing through people management practices. International Journal of Human Resource Management. 16, 720-735.

Carter, G., Scarborough, H., 2001. Towards a second generation of KM? The people management challenge. Education and Training. 43, 215-224.

Chourides, P., Longbottom, D., and Murphy, W., 2003. Excellence in knowledge management: an empirical study to identify critical factors and performance measures. Measuring Business Excellence. 7, 29-45.

Currie, G., Kerrin, M., 2003. Human resource management and knowledge management: enhancing knowledge sharing in a pharmaceutical company. International Journal of Human Resource Management. 14, 1027-1045.

Davenport, T. H., De Long, D. W. and Beers, M. C., 1998. Successful Knowledge Management Projects. Sloan Management Review. 39, 43.

Davenport, T. H., Prusak, L., 1998. Working knowledge: how organizations manage what they know, Harvard Business School Press. Boston, Mass.

Evans, C., 2003. Managing for knowledge HR's strategic role, Butterworth-Heinemann, Amsterdam. http://www.netlibrary.com/urlapi.asp?action=summary $\& v=1 \&$ bookid $=104749$.

Fey, C. F., Denison, D. R., 1999. Organizational culture and effectiveness: the case of foreign firms in Russia. Presented at Academy of International Business, Charleston, SC. 
Goffee, R., Jones, G., 1996. What Holds The Modern Company Together? Harvard Business Review. 74, 133.

Grundstein, M., 2008. Assessing the enterprise's knowledge management maturity level. International Journal of Knowledge and Learning. 4, 415-426.

Grundstein, M., Rosenthal-Sabroux, C., 2008. GAMETH ${ }^{\circledR}$ : A Process Modeling Approach to Identify and Locate Crucial Knowledge. In: The 12th World Multi-Conference on Systemics, Cybernetics and Informatics. Orlando, Florida, USA.

Hunter, L., Beaumont, P., and Lee, M., 2002. Knowledge management practice in Scottish law firms. Human Resource Management Journal. 12, 4-21.

Jung, J., Choi, I., and Song, M., 2007. An integration architecture for knowledge management systems and business process management systems. Computers in Industry. 58, 21-34.

Kaplan, B., 2010. Losing your minds: capturing, retaining and leveraging organizational knowledge, Ark Group. London; North Sydney.

Kelloway, E. K., Barling, J., 2000. Knowledge work as organizational behavior. International Journal of Management Reviews. 2, 287-304. $\begin{array}{cr}\text { Kirsch, } & \text { D., } \\ \text { http://it.toolbox.com/wiki/index.php/Knowledge_Rete }\end{array}$ ntion

Kong, E., Chadee, D., and Raman, R., 2011. The role of human resource practices in developing knowledge and learning capabilities for innovation: a study of IT service providers in India. In: 10th International Research Conference on Quality, Innovation \& Knowledge Management: Aligning Innovation in Developed and Emerging Economies. Kuala Lumpur, Malaysia.

Lee, H., Choi, B., 2003. Knowledge Management Enablers, Processes, and Organizational Performance: An Integrative View and Empirical Examination. Journal of Management Information Systems. 20, 179228.

Liebowitz, J., 1999. Key Ingredients to the Success of an Organization's Knowledge Management Strategy. Knowledge and Process Management. 6, 37-40.

Liebowitz, J., 2009. Knowledge retention: strategies and solutions, CRC Press. Boca Raton.

Liebowitz, J., 2011. http://www.kmworld.com/Articles/Editorial/Feature/K nowledge-retention-What-practitioners-need-to-know73363.aspx

Manpower Inc.,

2010. http://us.manpower.com/us/en/multimedia/TL100_KRT\%20Position\%20Paper_WEB_v2_tcm 12650681_tcm126-50681.pdf

Mathi, K., 2004. Key Success Factors for Knowledge Management. Lindau, Germany.
Nair, P., Prakash, K., 2009. Knowledge management: facilitators' guide, Asian Productivity Organization. Tokyo.

Nelson, K., McCann, J. E., 2010. Designing for knowledge worker retention \& organization performance. Journal of Management and Marketing Research. 1,1-18.

Nonaka, I., Takeuchi, H., 1995. The knowledge-creating company: how Japanese companies create the dynamics of innovation, Oxford University Press. New York.

Nonaka, I., Toyama, R., and Nagata, A., 2000. A firm as a knowledge-creating entity: a new perspective on the theory of the firm. Industrial and Corporate Change. $9,1$.

Pan, S. L., Scarborough, H., 1999. Knowledge Management in Practice: An Explanatory Case Study. Technology Analysis \& Strategic Management. 11, 359-374.

Skyrme, D., Amidon, D., 1997. The Knowledge Agenda. Journal of Knowledge Management. 1, 27-37.

Stankosky, M. A., Baldanza, C., 2000. Knowledge management: an evolutionary Architecture Toward enterprise engineering, International Council on Systems Engineering (INCOSE). Reston, VA.

Sveiby, K. E., 1997. The new organizational wealth: managing and measuring knowledge-based assets, Berret Koehir. San Francisco.

Wong, K. Y., Aspinwall, E., 2004. Characterizing knowledge management in the small business environment. Journal of Knowledge Management. 8, 44-61.

Wong, K. Y., Aspinwall, E., 2005. An empirical study of the important factors for knowledge-management adoption in the SME sector. Journal of Knowledge Management. 9, 64-82.

Wright,

A.,

2007. http://www.tva.gov/knowledgeretention/pdf/aging_wo rkforce.pdf 